\title{
ELEMENTOS DO MARKETING NA CAPTAÇÃO DE RECURSOS DO TERCEIRO SETOR
}

ELEMENTS OF MARKETING IN FUNDRAISING OF THIRD SECTOR

\section{LUCILA MARIA DE SOUZA CAMPOS}

Doutora em Engenharia de Produção pela Universidade Federal de São Carlos (UFSCAR). Rua Servidão Canarinho, 235, Rio Tavares - Florianópolis - SC - CEP 88048-440 E-mail: lucila@univali.br

RICARDO BOEING-DA-SILVEIRA

Mestre em Administração pela Universidade do Vale do Itajaí (Univali). Rua Duarte Schutel, 181, ap. 1.222, Centro - Florianópolis - SC - CEP 88015-640 E-mail: boeing@univali.br

\section{ROSILENE MARCON}

Doutora em Engenharia de Produção pela Universidade Federal de Santa Catarina (UFSC).

Rua Felipe Schmidt, 1.210, ap. 402, Centro - Florianópolis - SC - CEP 88010-002 E-mail: rmarcon@univali.br 


\section{RESUMO}

O crescimento do terceiro setor no Brasil e a disputa cada vez mais acirrada por recursos que financiem seus projetos acarretaram o desenvolvimento de ações de cunho anteriormente considerado de exclusividade do segundo setor (mercado), como segmentação de possíveis investidores,comunicação das atividades da organização à comunidade em geral e estratégias de marketing de relacionamento com seus doadores,visando ao estabelecimento de alianças duradouras e à garantia de financiamento em longo prazo. Entretanto,os vários ti pos de organizações sem fins lucrativos realizam tais atividades de diferentes modos, algumas em maior, outras em menor intensidade,tornando-as pertencentes a grupos específicos. Diante disso,investigaram-se as diferenças existentes entre a execução desses elementos de marketing em dois ti pos de fundações do terceiro setor de Santa Catarina identificados no Ministério Público. A análise dos resultados evidenciou que os dois grupos realizam a comunicação/promoção,a segmentação e o marketing de relacionamento de maneiras específicas,salvo algumas exceções,a lém de apresentarem falta de foco em sua finalidade,o que pode resultar em uma baixa captação de recursos,prejudicando a implementação de projetos.

\section{PALAVRAS-CHAVE}

Comunicação; Segmentação; Marketing de relacionamento; Terceiro setor; Captação de recursos.

\section{ABSTRACT}

The growth of the third sector in Brazil and the dispute for resources to finance its projects comes to develop actions to approximate the second (market) and third sector,such as segmentation of possible investors,communication of the activities of the organization to the community in general and strategies of marketing of relationship with its givers,aiming atthe establishmentof lasting alliances and the 
guarantee of financing in the long run. However,the differenttypes of non-profit organizations carry through such activities in different ways, some in greater, others in lesser intensity,becoming them pertaining the specific groups. Ahead of this,a research has investigated the differences between the executions of these elements of marketing in two types of foundations of the third sector of Santa Catarina State identified in the Public Minister. The analysis of the resultsevidenced that the two groups carry through the communication/promotion,segmentation and marketing of relationship in specific ways,saved some exceptions,besides presenting lack of focus in its purpose,whatcan cause low fundraising,harming the implementation of projects.

\section{KEYWORDS}

Communication; Segmentation; Relationshipmarketing; Third sector; Fundraising.

\section{INTRODUÇ ÃO}

Atualmente,a concorrência entre as organizações que fazem parte do terceiro setor - fundações, organizações não-governamentais, entidades privadas de assistência social e associações comunitárias - é crescente,intensa e se dá por duas perspectivas: a competição entre as organizações sem fins lucrativos e a competição destas para com as organizações com finalidades de lucro. Essas concepções podem ser definidas por alguns fatores correspondentes: primeiro,o próprio crescimento no número de organizações agrupadas no terceiro setor,o que cria uma maior dificuldade na disputa pela obtenção de recursos financeiros de terceiros que possibilitem o exercício de seus projetos; segundo,a concorrência entre organizações sem fins lucrativos e com fins lucrativos, que acontece quando o primeiro grupo decide oferecer bens comerciais com o propósito de alcançar lucros que financiem suas atividades e garantam a auto-sustentação, desviando essas organizações da obrigação de resgatar recursos de outras fontes, uma vez que tal feito também tem se tornado tarefa cada vez mais árdua de ser alcançada (TENÓRIO,I999; MURPHY J.,2000; MARCUELLO,200I; BRADLEY etal.,2003; SAYER,2004; SALLES; DELLAGNELO,2005).

Para tanto,esforços podem ser concentrados para incrementar ações que maximizem os processos produtivos na busca incessante por financiamento de projetos idealizados por essas organizações, as quais objetivam aspectos relacionados ao bem-estar da sociedade em geral,seja pela inserção de excluídos no mercado de trabalho,seja na prática de movimentos que promovam a preservação ambiental,seja por meio de atividades ligadas à saúde pública,à moradia,à segu- 
rança, ao saneamento, à educação, à economia,à cultura, dentre outros. Dessa forma,os recursos financeiros ganham destaque,possibilitando que todos os projetos previamente elaborados possam ser implementados em sua totalidade.

Muitas das organizações do terceiro setor,como fundações e associações, fazem uso de instrumentos que facilitam a direção,a liderança,a organização e o controle de suas rotinas de trabalho. Uma das ferramentas utilizadas e que podem auxiliar na obtenção dessas fontes de capital indispensáveis é o marketing. Muitos autores o definem das mais variadas maneiras,tentando encontrar conceitos que abranjam o maior número de atividades ligadas a ele. Kotler e Armstrong (2003, p. 3),por exemplo,afirmam que é "um processo administrativo e social pelo qual indivíduos e grupos obtêm o que necessitam e desejam, por meio de criação, oferta e troca de produtos e valor com os outros". Esses indivíduos e grupos,de uma maneira geral, podem ser avaliados como clientes, os quais propiciam a base do marketing - a troca.

O marketing no terceiro setor,de acordo com Newman e Wallender (I978), Shapiro (I978) e Schiavo (I999), difere-se,no entanto,da maneira como é praticado nas empresas privadas com fins lucrativos,onde o marketing permite mais vendas, as quais são revertidas em lucro. O lucro obtido pode ser distribuído entre os funcionários ou reinvestido,constituindo fontes de recursos. Nas organizações sem fins lucrativos, o excedente financeiro não é distribuído,e todo o montante proveniente de doações e/ou vendas é utilizado para elaboração e desenvolvimento de projetos.

Ações distintas podem ser analisadas nessa situação, pois uma ação de marketing que almeja o financiador de recursos,seja ele o governo seja uma instituição privada,é totalmente diferente de uma campanha que tem como intuito angariar fundos de cidadãos que possuem uma certa renda de uma determinada região,isto é,ações segmentadas para pessoas físicas devem ser elaboradas de forma diferenciada das estratégias desenvolvidas para buscar recursos oriundos do governo ou de pessoas jurídicas (SHELLEY; POLONSKY,2002). Diferenças também podem ser encontradas em obras em que o marketing promove uma causa social,como a conscientização sobre os perigos causados pelas drogas. Então,o marketing utilizado nas organizações do terceiro setor vai além da relação cliente-fornecedor, a qual caracteriza o mercado e que,apesar de possuir uma conexão com o marketing exercido nesse ambiente,apresenta um conjunto de metodologias específicas que devem ser levadas em consideração (SCHIAVO, I999). No mercado,o cliente é o fornecedor de recursos e no terceiro setor o cliente é o beneficiado,não o financiador.

Posicionamento de mercado,fortalecimento da marca,segmentação,marketing de relacionamento,endomarketing e estratégias do composto mercadológico são 
alguns dos elementos do marketing utilizados por organizações do mercado para que a empresa possa crescer e prosperar. Os elementos escolhidos neste trabalho (promoção/comunicação,segmentação e marketing de relacionamento) possuem importância distinta e merecem um estudo mais aprofundado. Peattie (2002) e Gainer e Padanyi (2002) certificam que a promoção (comunicação) utilizada por organizações do terceiro setor possui um grande potencial que deve ser explorado. Sargeant(I999a) identificou uma série de variáveis que demonstram as diferenças de comportamento entre as pessoas,reforçando a importância da segmentação de mercado,em que cada segmento possui características semelhantes,facilitando a elaboração de ações voltadas à retenção de clientes,mesmo quando se trata de organizações sem fins lucrativos. Para fechar o grupo de elementos a serem estudados,tem-se o marketing de relacionamento. Bowen etal. (I989) e Levitt(I990) reforçam a idéia de produto ampliado,defendendo que, para a conquista da diferenciação,não basta dar ao cliente o que ele espera,mas sim oferecer mais do que ele pensa que necessita ou do que se acostumou a esperar. No caso do terceiro setor,ações que gerem um relacionamento positivo e duradouro podem gerar parcerias que garantam a sobrevivência de tais organizações.

Constatou-se no Ministério Público que aproximadamente 50\% das fundações que prestaram contas no ano de 2004 possuíam características educacionais (eram voltadas ao desenvolvimento de educação e pesquisa),e o restante estava distribuído entre diversas funções (proteção ambiental,assistência ambiental, associação profissional,dentre outras). Isso possibilitou verificar a existência de diferenças no comportamento das variáveis mercadológicas entre esses dois ti pos de organizações do terceiro setor. Sendo assim,optou-se por analisar as fundações do Estado de Santa Catarina,e grupos de fundações foram predeterminados.

Pretendeu-se,neste estudo,analisar a promoção (comunicação), a segmentação e o marketing de relacionamento executados nesses dois grupos de organizações do terceiro setor do ti po fundação,considerando a captação de recursos para a concretização de atividades planejadas. Isso foi realizado por meio de uma metodologia de pesquisa interpretativa com características quantitativas.

\section{FUNDAMENTAÇÃO TEÓRICA}

Várias pesquisas analisaram a utilização da promoção,da segmentação e do marketing de relacionamento na captação de recursos,em organizações do terceiro setor. Gainer e Padanyi (2002), Stephens (2004), Higgins e Lauzon (2003), 
Rodrigues (1998),Popadiuk e Marcondes (2000),Arnold e Tapp (2003), Martinez (2003), Shelley e Polonsky (2002), Kotler e Levy (i969), Arnett et al. (2003), Varadarajan e Menon (I988), Sargeant(I995; 200I), Romney-Alexander (2002), Andreasen (1996), Murphy (2000a), Abdy e Barclay (2001), Kottasz (2004), Nichols (2004), Peattie (2002), Fonseca etal. (2005), Hamza etal. (2005) e Machado etal. (2005) encontraram em seus estudos subsídios para afirmar que esses três elementos exercem influência positiva em relação ao montante arrecadado. Já Shelley e Polonsky (2002) encontraram resultados contrários.

Para o correto gerenciamento das atividades de organizações do terceiro setor,faz-se necessário,de acordo com Marcuello (200I), ana lisar três aspectos de suma importância para a sua eficiência. O primeiro deles é a teoria das organizações,considerada um corpo científico do conhecimento,um sistema conceitual que estuda a realidade social e econômica das organizações,explicando suas estruturas e funções cientificamente. O segundo é a teoria econômica,que estuda as organizações e o fenômeno organizacional usando conceitos oriundos da teoria organizacional,do comportamento organizacional e de microeconomia. Essa doutrina oferece a base teórica para o entendimento que gerentes deveriam ter,como a locação de recursos e inter-relação estrutural. O terceiro aspecto refere-se ao gerenciamento estratégico que facilita a escolha de diferentes negócios e determina a forma como as empresas competem. Esse processo reúne características de design organizacional,escolha e implementação de estratégias, tomada de decisão,reestruturação,aprendizagem organizacional e objetivos de controle.

A preocupação com a gestão do negócio deve ser enfrentada da mesma forma que no setor privado, pois possui muitos componentes similares, como gerenciamento, clientes, recursos materiais, financeiros, técnicos e humanos (ANDRADE,2002; TENÓRIO,I999), já que os objetivos sociais,filantrópicos ou outro qualquer não podem ser tratados com descuido.

As técnicas de administração tradicionais,aplicadas tanto para o setor público como para o setor privado,encontram limitações quando são simplesmente transferidas para o terceiro setor. Nas organizações sociais, a ausência de lucro e de proprietário como foco central possibilita o predomínio de valores como a gestão partici pativa,a prioridade ao atendimento do público-alvo,o comprometimento com a missão,a valorização do ser humano e o comprometimento com o outro (HUDSON,I999; MEREGE,2000; TENÓRIO,I999).

Wolf (I999) cita que existem alguns meios pelos quais as organizações sem fins lucrativos obtêm financiamento: doações irrestritas e contribuições individuais, apoio corporativo, fundações e agências públicas, e doações em atraso. Várias ferramentas são utilizadas com objetivo de alcançar a concretização do 
financiamento para a implementação de projetos desenvolvidos por organizações do terceiro setor. Uma delas é o marketing,com sua gama variada de elementos que possibilitam a agregação de valor e a obtenção de vantagem competitiva no mercado. Mas será que,em um ambiente onde o lucro não é a finalidade,o marketing funciona dessa maneira?

Shapiro (1978) ressalta que,embora a função marketing se diferencie nas organizações sem fins lucrativos, certos conceitos de negócios podem ser adotados para realçar suas operações. Nas organizações sem fins lucrativos, o marketing é utilizado princi palmente na obtenção de recursos que auxiliem na implementação de projetos de cunho social. Kotler e Zaltman (I97I) tentaram enquadrar o marketing dentro de uma nova esfera,a social,e definiram-no como o projeto,a implementação e o controle de programas que procuram aumentar a aceitação de uma idéia,causa ou prática social entre um grupo-alvo,utilizando conceitos de segmentação e comunicação,a fim de maximizar a reação de tal grupo.

Segundo Cruz e Straviz (2000),uma gestão profissionalizada em organizações do terceiro setor requer a estruturação da área de captação de recursos. A organização necessita,num primeiro momento,levantar a história e os antecedentes no seu processo de obtenção de recursos. Também é importante que se conheçam os possíveis financiadores, as fontes com possibilidade de prover um maior financiamento, as que podem restringi-lo e as que mais se identificam com a instituição. Esse processo tem como objetivo buscar a diversificação do portfólio de financiadores da organização,evitando sua dependência financeira a uma única fonte.

Valarelli (2002) afirma que a referida obtenção de fundos será tão mais eficaz quanto mais ampla for a noção de recursos da instituição e quanto mais diversificada e adequada às suas características e ao ambiente externo for a ação de captação de recursos. O autor conceitua captação como diversas ações para este fim,como patrocínios, doações, parcerias, prestação de serviços, venda de produtos,entre outras,não limitando a obtenção de fundos a práticas de caráter mais permanente como é comum acontecer. É necessário entender recursos, porém não somente como recursos financeiros, mas também materiais, humanos,entre outros.

Em relação à captação de recursos,várias fontes podem ser procuradas,a fim de estabelecer parcerias. O Quadro I apresenta algumas fontes de obtenção de lucros,formas de partici pação,meios e estratégias que podem ser desenvolvidos para a obtenção de fundos. 
QUADRO I

MANEIRAS DE CAPTAÇÃ DE RECURSOS

\begin{tabular}{|c|c|c|c|}
\hline FONTES & $\begin{array}{l}\text { FORMAS DE } \\
\text { PARTICIPAÇÃO }\end{array}$ & MEIOS & ESTRATÉGIAS \\
\hline $\begin{array}{l}\text { ONG } \\
\text { financiadoras } \\
\text { nacionais }\end{array}$ & $\begin{array}{l}\text { Projetos } \\
\text { Prêmios } \\
\text { Convênios }\end{array}$ & $\begin{array}{l}\text { Visita pessoal } \\
\text { Telefone } \\
\text { Correio } \\
\text { E-mail }\end{array}$ & $\begin{array}{l}\text { Boa elaboração do projeto } \\
\text { Garantia de impacto social }\end{array}$ \\
\hline $\begin{array}{l}\text { ONG } \\
\text { financiadoras } \\
\text { internacionais }\end{array}$ & $\begin{array}{l}\text { Projetos } \\
\text { Prêmios } \\
\text { Convênios }\end{array}$ & $\begin{array}{l}\text { Visita pessoal } \\
\text { Telefone } \\
\text { Correio } \\
\text { E-mail }\end{array}$ & $\begin{array}{l}\text { Boa elaboração do projeto } \\
\text { Garantia de impacto social } \\
\text { Redação adequada à } \\
\text { língua }\end{array}$ \\
\hline $\begin{array}{l}\text { Órgãos } \\
\text { governamentais }\end{array}$ & $\begin{array}{l}\text { Projetos } \\
\text { Convênios }\end{array}$ & $\begin{array}{l}\text { Visita pessoal } \\
\text { Telefone } \\
\text { Correio } \\
\text { E-mail }\end{array}$ & $\begin{array}{l}\text { Boa elaboração do projeto } \\
\text { Garantia de impacto social }\end{array}$ \\
\hline Empresas & $\begin{array}{l}\text { Doações únicas } \\
\text { Contribuições mensais } \\
\text { Projetos especiais } \\
\text { Campanhas } \\
\text { Patrocínios de eventos } \\
\text { Prêmios }\end{array}$ & $\begin{array}{l}\text { Visita pessoal } \\
\text { Mala direta } \\
\text { Marketing } \\
\text { Telefone } \\
\text { Correio } \\
\text { E-mail }\end{array}$ & $\begin{array}{l}\text { Sensibilização } \\
\text { Boa elaboração de projeto } \\
\text { Garantia de impacto social } \\
\text { Formação de parcerias }\end{array}$ \\
\hline Pessoas físicas & $\begin{array}{l}\text { Doações únicas } \\
\text { Contribuições mensais } \\
\text { Voluntariado } \\
\text { Participação em } \\
\text { eventos } \\
\text { Compra de produtos }\end{array}$ & $\begin{array}{l}\text { Visita pessoal } \\
\text { Mala direta } \\
\text { Telemarketing } \\
\text { Produtos próprios } \\
\text { Telefone } \\
\text { Campanhas } \\
\text { Catálogos } \\
\text { Eventos } \\
\text { Telefone } \\
\text { Correio } \\
\text { E-mail }\end{array}$ & $\begin{array}{l}\text { Sensibilização e } \\
\text { mobilização por: } \\
\text { Culpa } \\
\text { Satisfação pessoal } \\
\text { Apelo da mensagem } \\
\text { Obrigação } \\
\text { Afinidade com a causa } \\
\text { Status }\end{array}$ \\
\hline
\end{tabular}

Fonte: Adaptado de Dearo (2004).

Adaptando o composto mercadológico às organizações do terceiro setor, têm-se: produto (programas e serviços oferecidos), promoção (comunicação realizada para promover tais programas e serviços), preço (ou quanto custa para 
partici par ou elaborá-lo) e praça (ou onde os produtos,programas e serviços estão disponíveis) (WOLF,I999).

Kotler (I978) ressalta que na promoção,por abranger o contato pessoal,a propaganda,a publicidade e a promoção de vendas, todos devem estabelecer padrões que conquistem suas metas (que no caso desta pesquisa é a captação de recursos),devendo selecionar seu público-a lvo e as mídias a serem utilizadas.

Nichols (2004), Peattie (2002), Hamza etal. (2005), Machado etal. (2005), Murphy (2000a), Desmet (I999) e Andrade (2002) ressaltam a importância da promoção (comunicação) em organizações sem fins lucrativos não somente como estratégia de captação de recursos,mas como atividade primordial de incremento contínuo da imagem da organização,facilitação do estabelecimento de parcerias e implementação de projetos desenvolvidos.

Outras ações são consideradas extremamente importantes para a maximização dos resultados organizacionais. Escolher o público-alvo e direcionar estratégias a ele pode ser crucial na conquista de clientes,uma vez que todas as atenções serão focadas às suas necessidades. A segmentação de mercado possibilita essa realidade,permitindo uma maior interação da empresa com seus consumidores. Pesquisas realizadas por Kottasz (2004), Nichols (2004), Andreasen (I996), Romney-Alexander (2002), Sargeant (I995; I999a), Kotler e Levy (I969), Higgins e Lauzon (2003), Wagner e Ryan (2004) e Desmet(I999) constataram a importância de segmentar mercados e,com isso,atrair recursos de forma fácil e eficiente. Como resultado,obtiveram-se a segregação de grupos com características similares e maior quantidade de dinheiro arrecadado.

Rodrigues (I998),Arnold e Tapp (2003), Martinez (2003),Arnettetal. (2003), Varadarajan e Menon (I988),Sargeant(I999b; 200I), Romney-Alexander (2002), Andreasen (1996), Nichols (2004), Fonseca etal. (2005), Machado etal. (2005), Abdy e Barclay (200I), Sargeante Lee (2002) e Fisher (2005) encontraram em suas pesquisas resultados similares no tocante ao marketing de relacionamento e à formação de parcerias/a lianças para a captação de recursos. Isso vem reforçar a importância desse elemento do marketing para as organizações do terceiro setor e para a continuidade de seus projetos,visto que o número de concorrentes em busca de recursos externos cresce a cada dia.

Várias estratégias se fazem necessárias para que os recursos pretendidos sejam captados e os projetos estabelecidos possam ser viabilizados. Alguns autores (PEATTIE, 2002; MARTINEZ,2003; SHELLEY; POLONSKY, 2002; ARNETT etal.,2003) citam ações de marketing que são utilizadas por organizações que desejam incrementar seu orçamento financeiro,buscando recursos com pessoas físicas e jurídicas. Sendo assim,a função marketing deve ser tratada de maneira especial,já que pode ocasionar importantes diferenciais no momento da captação. 


\section{METODOLOGIA}

Esta pesquisa é quantitativa,exploratória e descritiva,e pode ser caracterizada como um levantamento de campo survey,realizado ex post facto. Para análise dos elementos da função marketing estudados nesta pesquisa,foram utilizadas três categorias de variáveis: segmentação,promoção ou comunicação e marketing de relacionamento,levando-se em consideração a captação de recursos.

Dois grandes conjuntos com características similares foram identificados antes do estabelecimento da situação problema,quando se resgatou,em dezembro de 2004, uma relação com os nomes das fundações que prestaram contas ao Ministério Público naquele ano. Percebeu-se que aproximadamente 50\% das fundações tinham como finalidade o desenvolvimento da educação e pesquisa. As organizações que apresentavam causas voltadas à educação foram então denominadas "fundações educacionais" e às organizações com causas diferentes atribuiu-se o nome de "fundações não-educacionais".

Procurou-se adaptar as respostas obtidas ao método mais conveniente,almejando o alcance dos resultados esperados. Como o objetivo geral foi analisar o comportamento da promoção,da segmentação e do marketing de relacionamento nos dois grupos estudados (fundações educacionais e não-educacionais) em relação à captação de recursos,optou-se pela utilização da análise estatística multivariada.

O procedimento utilizado para aplicação da análise discriminante é descrito a seguir,que,de acordo com Corrar (2004),foi:

I) Ajustar um modelo discriminante linear (pelo método dos mínimos quadrados):

$$
Z_{i}=\beta_{0}+\beta_{1} X_{1}+\beta_{2} X_{2}+\ldots+\beta_{k} X_{k}, \quad[I]
$$

Em que:

$\mathrm{Z}_{\mathrm{i}}$ : escore discriminante referente à i-ésima empresa,i=I,2,..,n.

$\mathrm{X}_{\mathrm{i}}$ : variável independente referente à i-ésima empresa.

$B_{0}$ : intercepto do modelo;

$\beta_{\mathrm{j}}$ : parâmetro do modelo (ou coeficiente discriminante) associado à j-ésima variável $(j=\mathrm{I}, 2, \ldots, \mathrm{k})$.

2) Estimar os escores discriminantes a partir do modelo ajustado.

3) Calcular o escore crítico (ou ponto de corte) dado por:

$$
\mathrm{z}_{\text {crítico }}=\frac{\mathrm{n}_{1} \overline{\mathrm{Z}}_{2}+\mathrm{n}_{2} \overline{\mathrm{Z}}_{1}}{\mathrm{n}_{1}+\mathrm{n}_{2}} \quad \text { [2] }
$$


Em que:

$\mathrm{n}_{1}$ : número de empresas do grupo I: fundações educacionais;

$\mathrm{n}_{2}$ : número de empresas do grupo 2: fundações não-educacionais;

$\bar{Z}_{1}$ : média dos escores discriminantes do grupo I: fundações educacionais;

$\bar{Z}_{2}$ : média dos escores discriminantes do grupo 2: fundações não-educacionais.

4) Aplicar a seguinte regra de decisão/classificação: Se $Z_{i}<Z_{\text {crítico, }}$ a empresa é classificada como pertencente ao grupo I,ou seja,é classificada como fundações educacionais. Se crítico $\mathrm{Z}_{\mathrm{i}}>\mathrm{Z}_{\text {crítico, }}$ a empresa é classificada como pertencente ao grupo 2,ou seja,é classificada como fundações não-educacionais.

5) Por último,foi feita uma avaliação do poder de discriminação do modelo ajustado em relação à a locação correta das empresas entre os grupos considerados.

PerreaultJunior etal. (I979) e Castro Junior (2003) realizaram pesquisas tendo como método a análise discriminante,em que grupos com características diferentes foram separados,com intenção de encontrar peculiaridades que pudessem defini-los como pertencentes a este ou àquele grupo. O objeto desta análise é a locar um indivíduo em um dos grupos estudados com base nas suas mensurações (HAIR JUNIOR etal.,2005).

Foram necessárias algumas alterações no presente estudo,visto que a análise discriminante clássica é específica para dados quantitativos,e os dados deste trabalho são qualitativos,pois utilizou-se uma escala de Likertcom cinco pontos para identificação das qualidades e preferências dos respondentes. Machado e Verdinelli (2004) sugerem a aplicação de uma derivação do método,denominada discriminante qualitativa -DISQUAL. Para tal feito,processaram-se pela análise de correspondência múlti pla os dados qualitativos; em seguida,foram "retidos os escores fatoriais desta aplicação para desenvolver,com esta nova base já transformada em dados quantitativos,a análise discriminante final e a posterior equação linear" (MACHADO; VERDINELLI,2004,p. 6).

Todas as organizações que constavam no relatório do Ministério Público foram pesquisadas, totalizando II3,almejando-se então a obtenção de um censo, ou toda a população de organizações existentes. Destas II3,64 eram fundações com características educacionais e 49 fundações com características não-educacionais. O critério de escolha das organizações pesquisadas se deu pelo fato de estarem situadas na mesma região e possuírem dados num órgão de controle governamental (no caso,o Ministério Público). Os questionários foram enviados por e-mail,além de duas ligações para cada organização reforçando a importância da pesquisa para o desenvolvimento do trabalho. Aplicou-se também um pré- 
teste em oito organizações da grande Florianópolis,com o objetivo de obter as validações de semântica e de juízo.

A variável dependente "captação de recursos" foi utilizada como base para diferenciar o comportamento das duas variáveis independentes. Higgins e Lauzon (2003), Sargeant (I999b; 200I), Murphy (2000b), Kingston e Bolton (2004), Tyminski (I995), Wayson (I998), O’Heffernan (2000), Nichols (2004), Stephens (2004), Levy (2004), Weisbroad (I998), Fay (2001) e Franco etal. (2003) reforçam a importância da captação de recursos e o uso de atividades mercadológicas para o incremento do montante arrecadado por organizações do terceiro setor. Sendo assim,optou-se por esta variável para que se pudessem obter informações mais precisas quanto ao uso das ferramentas comentadas anteriormente e de suas diferenças em cada grupo de fundações pesquisadas.

O questionário aplicado durante a pesquisa foi elaborado com o auxílio do levantamento bibliográfico sobre o assunto e classificado da seguinte forma: parte I - perfil das organizações pesquisadas; parte 2 -meios de comunicação, fontes de financiamento e estabelecimento de parcerias; parte 3 -a promoção nas organizações do terceiro setor; parte 4 -a segmentação como estratégia de captação de recursos; e parte 5-o marketing de relacionamento nas organizações do terceiro setor.

Nesta pesquisa,utilizou-se o aplicativo estatístico Statistica que trabalha com conceitos de aplicação da análise discriminante (AD) para variáveis qua litativas. A partir dos dados originais,o aplicativo gerou internamente uma matriz disjuntiva completa e,então,aplicou-se uma análise correspondente múltipla (ACM). As coordenadas dos respondentes sobre os eixos fatoriais gerados na análise de correspondência formaram a nova matriz de dados a serem discriminados.

\section{RESULTADOS}

Deve-se ressaltar que a quantidade de organizações respondentes corresponde a 4I organizações,2I consideradas educacionais e 20 não-educacionais. Destas 20,somente duas definiram-se como exclusivamente voltadas à cultura e recreação,o restante (I8) assinalou mais de uma opção. Isso gerou maior disparidade de respostas, já que todas as fundações classificadas como educacionais apontaram somente a opção educação e pesquisa como a sua área de atuação, mas muitas das demais fundações, previamente denominadas como não-educacionais,assinalaram mais de uma opção.

Tal fato leva à reflexão sobre a dificuldade de gerenciamento e até mesmo de captação de recursos. Por não possuírem uma causa bem definida,muitos projetos não conseguem financiamento,tornando necessário o repensar dos objetivos da organização para aumentar o foco da área de atuação. O item do questionário 
ligado às fontes de financiamento das fundações exigia que estas respondessem qual a porcentagem que melhor representava a composição das fontes de recursos financeiros em 2004. Essa questão também foi prejudicada,visto que a grande maioria não apresentou esses dados. Tentou-se estabelecer uma média da composição das fontes de financiamento entre as fundações pesquisadas. Nesta parte,houve respostas por parte das 4I organizações. Entretanto,na pergunta seguinte, que questionava sobre o montante de recursos utilizados em 2004, somente 22 apresentaram respostas.

Pôde-se perceber que a maior origem de recursos é oriunda de receitas próprias. Como 2I fundações pertencem ao grupo educacional,uma das razões para que isso aconteça deve-se ao fato de estas captarem recursos pelo pagamento de mensalidades dos cursos ofertados, já o governo vem em segundo lugar. Nesse caso,grande parte das fundações educacionais afirmou resgatar recursos oriundos do governo,a lém das não-educacionais,que recebem bastante auxílio desse órgão também. As demais fontes estão relacionadas às duas fundações,algumas em maior e outras em menor escala. As doações de empresas privadas e indivíduos aparecem mais no grupo não-educacional. Percebe-se uma diferença em relação à pesquisa realizada por Andrade (2002) que,em seu estudo,pesquisou organizações de assistencialismo,que dependem muito mais de doações de empresas privadas e indivíduos. Em seus resultados,constatou-se que a maior fonte de recursos vinha de empresas privadas,com 43,32\%, seguida de indivíduos,com 33,28\%. Isso demonstra uma diferença significativa na origem de recursos entre esses ti pos de organização e as fundações aqui estudadas,visto que suas maiores fontes de recursos são as receitas próprias e o governo. Salles e Dellagnelo (2005) perceberam em seus achados que empresas privadas e órgãos governamentais são considerados destaques como fontes de recursos (nesse caso,as organizações pesquisadas foram três com área de atuação ambientalista, diferenciando-se também da maioria das fundações analisadas neste trabalho).

No caso da presente pesquisa, para transformar os dados semânticos em quantitativos,foi necessário gerar uma matriz disjuntiva completa a partir dos quadros com as respostas de cada fundação. Após feita essa transformação,os dados se processaram pela análise de correspondência (AC),que utiliza como informação de partida uma matriz de dados qualitativos de $n$ linhas ou observações por $p$ colunas (soma das modalidades de todas as variáveis). O objetivo foi sintetizar a informação contida nessa matriz,nomeadamente,identificando relações de ordem entre as variáveis e possíveis redundâncias da informação. De modo indireto,pretendeu-se reduzir a dimensionalidade do espaço em que os indivíduos e propriedades estão projetados,perdendo-se o mínimo de informação.

No caso da tabela disjuntiva completa,o número de informações existentes passou de 24 para I20 (cinco opções em cada item,visto que a escala de Likert possuía variação de um a cinco). Após a AC,observou-se a inércia (variância) 
acumulada pelos fatores e foi decidido trabalhar com os dez primeiros fatores (> $85 \%$ da variância). Assim,reduziu-se o número de I2o para Io e obtiveram-se $85 \%$ das informações totais.

Utilizando-se o software Statistica,copiaram-se as coordenadas das fundações para os dez primeiros fatores e usou-se a matriz original para o cálculo da análise discriminante (AD). Esta foi calculada com base na variável grupo ("ne" versus "e") e as coordenadas dos dez fatores (FI a Fio). Observaram-se os seguintes dados: dez fatores no modelo; dois grupos ("ne" versus "e"); $\lambda$ de Wilk igual a $0, \mathrm{I} 5938$ aprox. $\mathrm{F}(\mathrm{IO}, 30)=\mathrm{I} 5,823 \mathrm{p}<0,0000$.

Nesse caso,o $\lambda$ de Wilk corresponde a um teste de significância e é distribuído como o qui quadrado $\left(\chi^{2}\right)$. Pode-se comprovar,então,que somente os dez primeiros fatores são significativos para uma significância de $5 \%$, mas, se for escolhido trabalhar com $\mathrm{I} \%, \mathrm{o}$ fator 6 deixaria de ser significante $(\mathrm{p}=0,0209)$ $\mathrm{O}, \mathrm{OI}=\alpha)$. Nesse caso,levaram-se em consideração os três elementos do marketing aqui trabalhados e as 24 questões do instrumento. A seguir,pode-se visualizar o Gráfico I para os grupos de fundações não-educacionais (“ne”).

\section{GRÁFICO I}

FUNÇÃO DISCRIMINANTE PARA O GRUPO DE FUNDAÇÕES NÃO-EDUCACIONAIS ("NE")

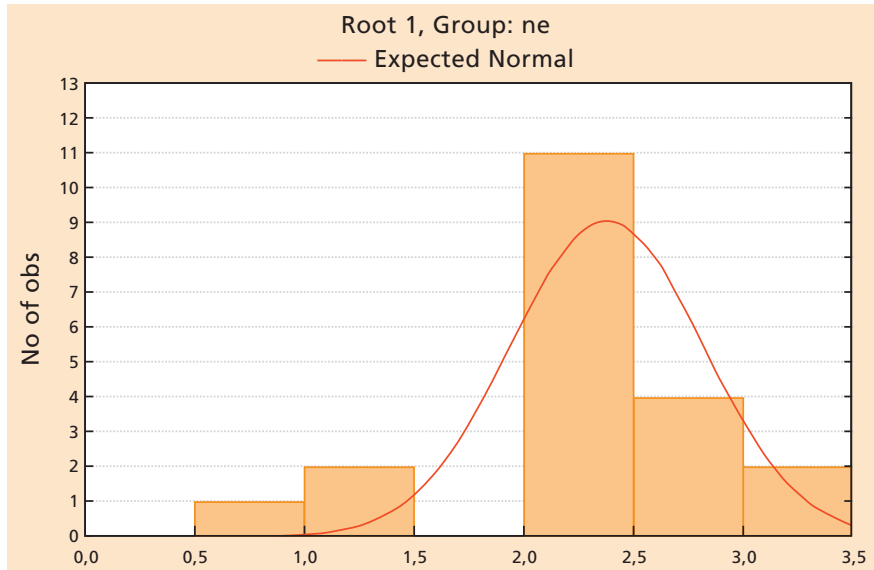

Todas as fundações classificadas como não-educacionais apresentam sinal positivo quando se calcula a função discriminante. Na vertical,percebe-se a quantidade de fundações,e na horizontal,o valor da função discriminante,e a curva normal é distribuída simetricamente. O centróide para o grupo "ne" localiza-se próximo à coordenada $+2,0$ (valor médio para os escores $\mathrm{Z}$ discriminantes em um dado grupo,de acordo com Hair Junior etal.,2005).

Para o grupo das fundações educacionais,tem-se o Gráfico 2. 


\section{GRÁFICO 2}

FUNÇÃO DISCRIMINANTE PARA O GRUPO DE FUNDAÇÕES EDUCACIONAIS (“E”)

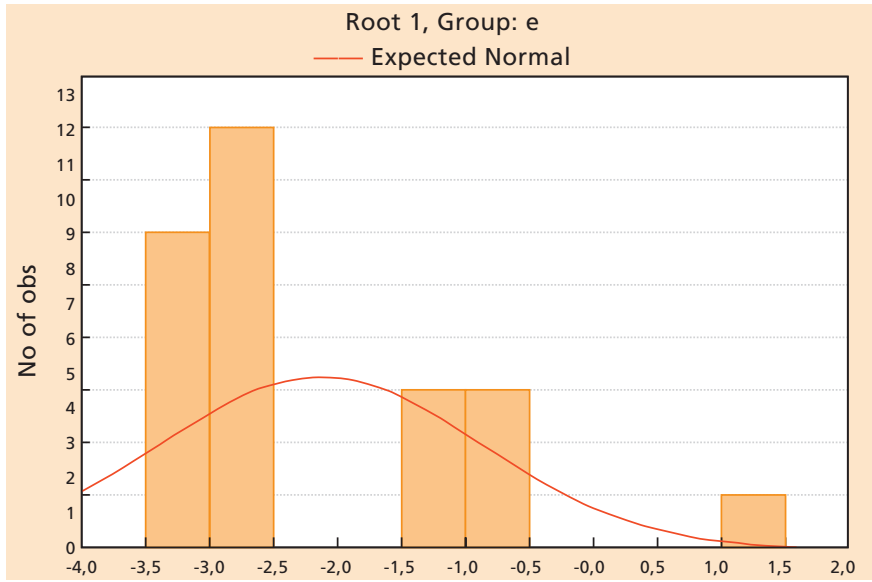

Nesse caso,a curva normal apresenta assimetria,e observa-se que a maioria das fundações encontra-se com o valor da função discriminante negativo e apenas uma mal classificada,com o valor positivo. O centróide desse grupo localizase próximo a -2,5(HAIR JUNIOR etal.,2005).

Os gráficos 3 e 4,relacionados à promoção/comunicação no grupo de fundações não-educacionais ("ne”) e educacionais ("e”) pesquisadas,são apresentados a seguir.

\section{GRÁFICO 3}

FUNÇÃO DISCRIMINANTE PARA O GRUPO DE FUNDAÇÕES NÃOEDUCACIONAIS ("NE") EM RELAÇÃO A PROMOÇÃO/COMUNICAÇÃO

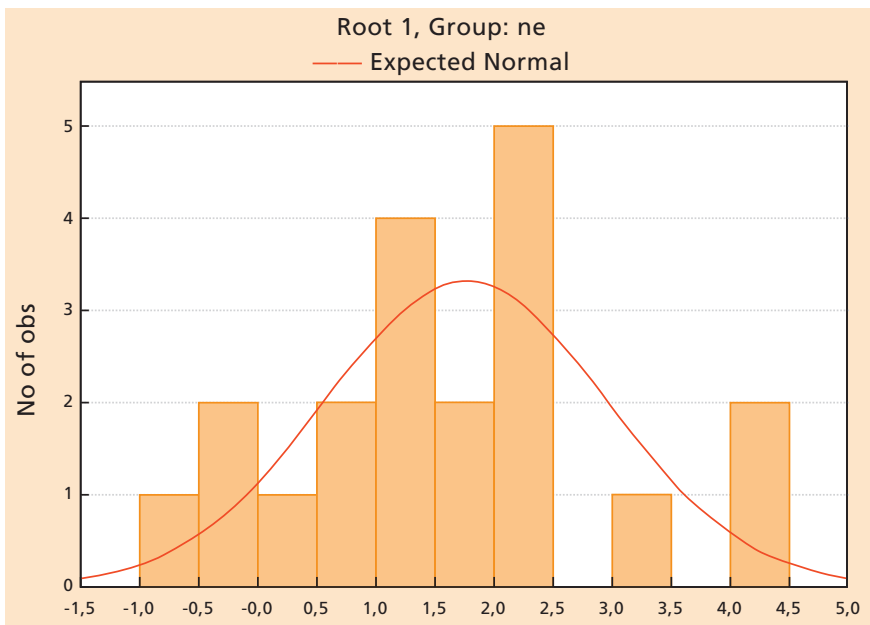


Analisando-se somente a promoção,percebe-se que três fundações foram mal classificadas,tendo em vista que na parte vertical está a quantidade de fundações e na horizontal o valor da função discriminante. Verifica-se também que a curva normal apresenta perfeita simetria. O centróide,nesse caso,está localizado próximo de 2,0. Essas três fundações observadas como mal classificadas utilizam a promoção como fundação pertencentes ao grupo educacional. A seguir,observa-se o Gráfico 4 para o grupo das fundações educacionais ("e").

\section{GRÁFICO 4}

FUNÇÃO DISCRIMINANTE PARA O GRUPO DE FUNDAÇÕES EDUCACIONAIS ("E”) EM RELAÇÃO A PROMOÇÃO/COMUNICAÇÃO

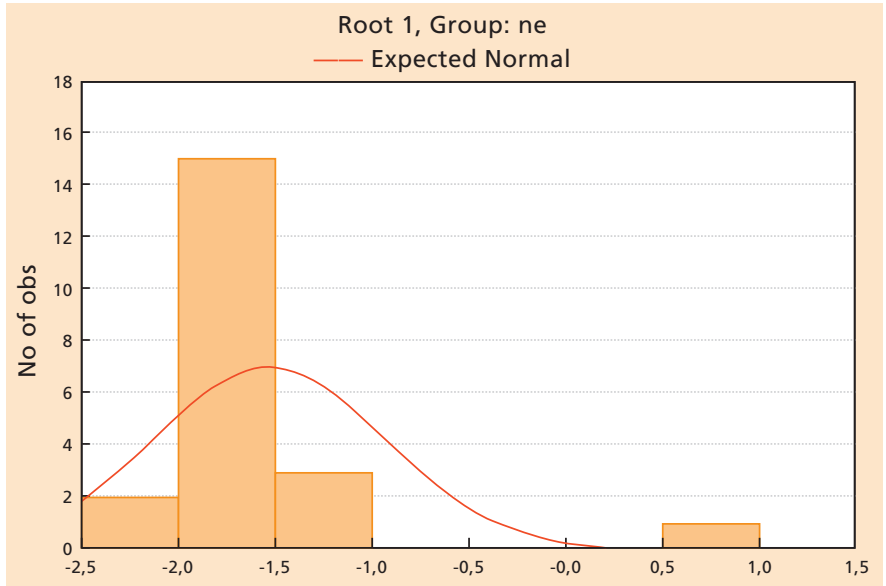

Nesse caso,apenas uma fundação foi mal classificada,quando se leva em consideração a promoção/comunicação. O centróide está próximo de $-\mathrm{I}, 5 \mathrm{e}$ a curva normal também apresenta simetria. Essa observação leva a crer que essa fundação trabalha as ações de promoção como se fosse uma "ne".

Os gráficos 5 e 6,relacionados à segmentação no grupo de fundações nãoeducacionais ("ne") e educacionais ("e") pesquisadas,são apresentados a seguir, respectivamente. 


\section{GRÁFICO 5}

\section{FUNÇÃO DISCRIMINANTE PARA AS FUNDAÇÕES NÂO-}

EDUCACIONAIS EM RELAÇÃO A SEGMENTAÇÃO

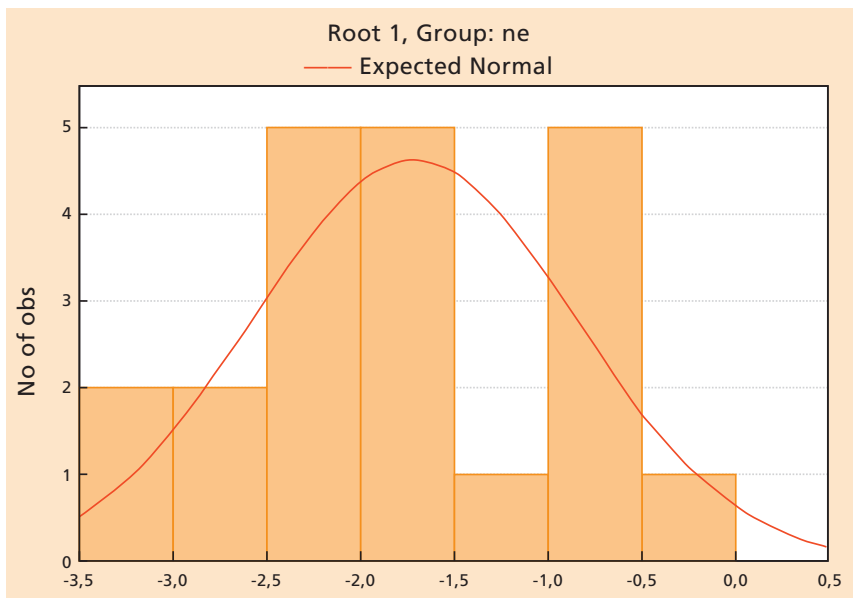

Ao se analisar somente a segmentação,percebe-se que o valor da função discriminante fica negativo e nenhuma fundação é classificada erroneamente, podendo-se concluir que todas elas segmentam seus públicos de maneira similar. O centróide,nesse caso,está localizado próximo de -2,o e a curva normal apresenta simetria perfeita. A seguir,observa-se o Gráfico 6 para o grupo das fundações educacionais ("e").

\section{GRÁFICO 6}

\section{FUNÇÃO DISCRIMINANTE PARA AS FUNDAÇÕES} EDUCACIONAIS ("E") EM RELAÇÃO A SEGMENTAÇÃO

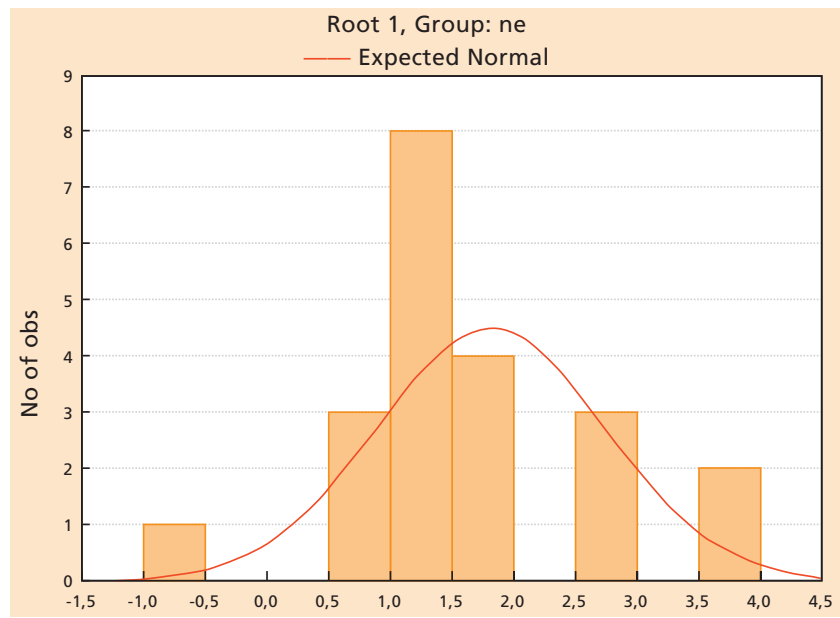


Quando se analisa a segmentação,verifica-se que a função discriminante assume valor positivo e apenas uma fica mal classificada. O centróide está próximo de I, 5 e a curva normal também se apresenta simétrica. Essa observação leva a crer que essa fundação trabalha as ações de segmentação como se fosse uma "ne". Percebeu-se que a mesma fundação que apresentou anteriormente problemas de classificação demonstrou falhas no desenvolvimento de suas ações, tanto de promoção/comunicação como de segmentação,visto que,em todas as análises posteriores ao cálculo da função discriminante,esta apresentou-se mal classificada.

Depois de realizado o cálculo das funções discriminantes,podem-se perceber as diferenças ocasionadas pelos dois resultados originados. Quando se têm a análise de correspondência e,posteriormente,a análise discriminante,a confiabilidade dos resultados aumenta,pois ela identifica as variáveis com as maiores diferenças entre os grupos e determina um coeficiente discriminante que pondera cada variável para refletir essas diferenças,possibilitando a máxima separação possível entre estes.

Os gráficos 7 e 8 correspondentes ao marketing de relacionamento nos dois grupos pesquisados (“ne”) e (“e”) são apresentados a seguir.

\section{GRÁFICO 7}

FUNÇÃO DISCRIMINANTE PARA O GRUPO DE FUNDAÇÖES NÃO-EDUCACIONAIS ("NE") EM RELAÇÃO AO MARKETING DE RELACIONAMENTO

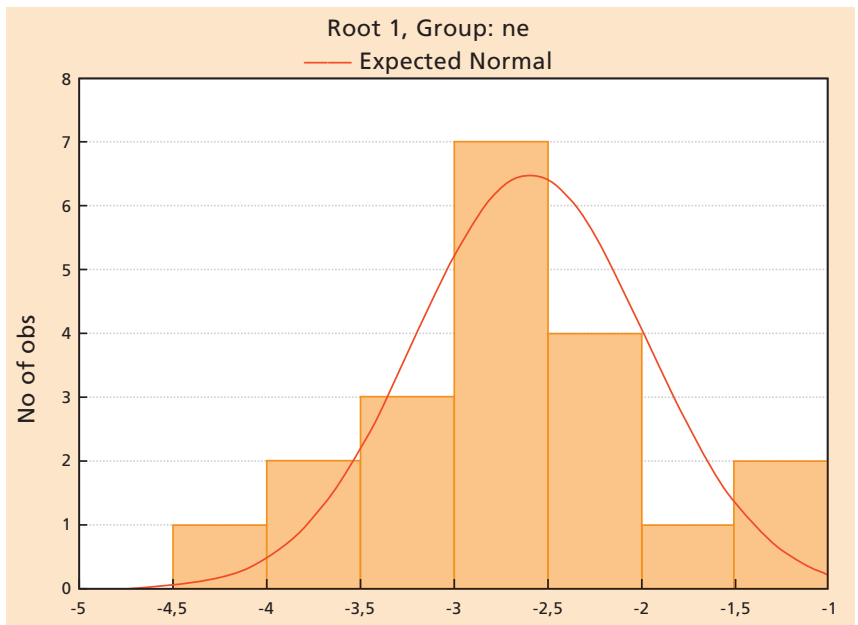

Quando se verifica somente o marketing de relacionamento,percebe-se que o valor da função discriminante fica negativo e nenhuma fundação é classificada 
erroneamente. Com base nisso,pode-se concluir que essas fundações trabalham suas trocas relacionais e o estabelecimento de alianças de modo similar. O centróide,nesse caso,está localizado próximo de -2,5e a curva normal apresenta simetria perfeita. A seguir,observa-se o Gráfico 8 para o grupo das fundações educacionais ("e").

\section{GRÁFICO 8}

FUNÇÃO DISCRIMINANTE PARA O GRUPO DE FUNDAÇÕES EDUCACIONAIS ("E”) EM RELAÇÃO AO MARKETING DE RELACIONAMENTO

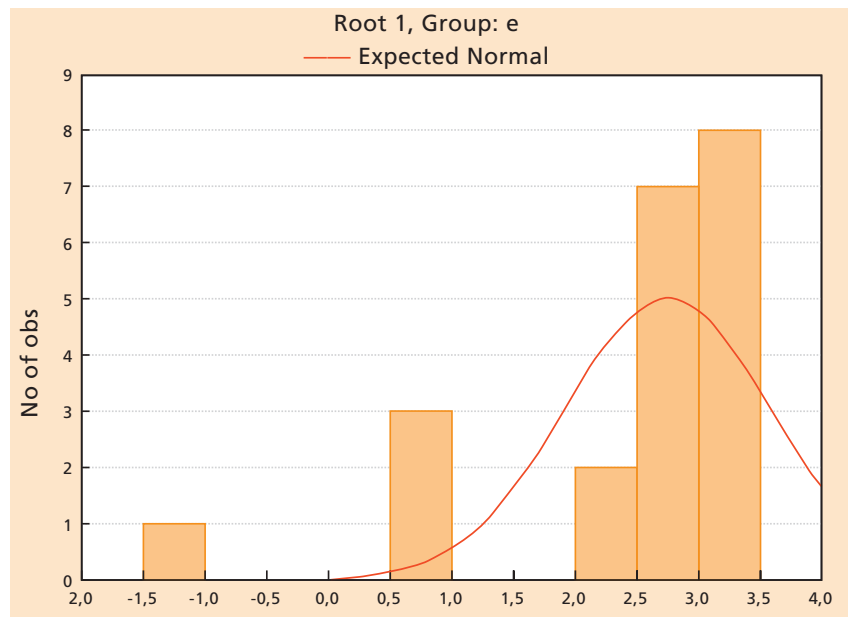

Quando se verifica o marketing de relacionamento no Gráfico 8,percebe-se que a função discriminante assume valor positivo e apenas uma fica mal classificada. O centróide está próximo de 3 e a curva normal também se apresenta simétrica. Essa observação sugere que a referida fundação trabalha as ações de marketing de relacionamento como se fosse uma "ne".

\section{CONSIDERAÇÕES FINAIS}

O presente trabalho teve como objetivo verificar se o comportamento da segmentação,do marketing de relacionamento e da promoção nos dois grupos pesquisados de organizações do terceiro setor em Santa Catarina era discriminatório,quando levado em conta a captação de recursos. Uma amostra de 4I fundações de todo o Estado de Santa Catarina serviu de base ao estudo.

Alguns resultados encontrados diferenciaram-se da teoria,como no caso do baixo índice de captação de recursos por projetos e,conseqüentemente,menor 
estabelecimento de alianças. Na presente pesquisa,percebeu-se também que as alianças são pontos-chave para o incremento do montante captado.

Em relação às percepções que levaram à análise discriminante,pode-se constatar que a maioria dos pesquisados de ambos os grupos tende a desenvolver os elementos do marketing aqui em estudo de modo semelhante. Uma fundação se denominou como educacional,mas,em todas as análises da função discriminante,ela foi enquadrada como mal classificada.

As análises feitas no decorrer deste artigo comprovaram que muitas fundações ainda não observam as ações mercadológicas aqui descritas como deveriam,deixando de utilizá-las muitas vezes por despreparo de sua equi pe. Outra observação interessante foi em relação aos montantes arrecadados. A maioria das fundações não respondeu a esse item,mas as que apresentaram suas quantias surpreenderam tanto pela grande cifra demonstrada como pela falta de ações de captação de recursos,o que gerou uma relação antagônica e um tanto quanto suspeita.

Observando as limitações e dificuldades encontradas no processo de análise das fundações,destaca-se que os resultados alcançados serviram para que se verificasse como as atividades mercadológicas em questão são desenvolvidas. A partir deste estudo,evidenciam-se novas perspectivas para aprofundamento de pesquisas tanto em outras fundações como em outras organizações do terceiro setor,assistenciais ou não.

Assim,vislumbram-se novos estudos como os destacados a seguir: a realização de pesquisas semelhantes a estas em outras fundações e outros ti pos de organizações do terceiro setor,destacando-se primeiramente os grupos aos quais pertencem e verificando suas diferenças; a comparação entre diferentes ti pos de organizações do terceiro setor, de finalidades diferentes,utilizando-se o mesmo método; e o aprofundamento do estudo sobre captação de recursos e atividades mercadológicas por meio de uma pesquisa qualitativa,para que se possam verificar a fundo suas dinâmicas e dificuldades.

\section{REFERÊNCIAS}

ABDY,M.; BARCLAY,J. Marketing collaborations in the voluntary sector. International Journal of Nonprofit and Voluntary Sector Marketing,v. 6,n. 3,p. 215-230,200I.

ANDRADE,M. G. V. de. Organizações do terceiro setor: estratégias para captação de recursos junto às empresas privadas. 2002. Dissertação (Mestrado) - Universidade Federal de Santa Catarina, Santa Catarina,2002.

ANDREASEN,A. R. Profits for nonprofits: find a corporate partner. Harvard Business Review,p. 47-59,Nov./Dec. 1996. 
ARNETT,D. B.; GERMAN,S. D.; HUNT,S. D. The identity salience modelo of relationship marketing success: the case of nonprofitmarketing. Journal of Marketing,v. 67,p. 89-I05,Apr. 2003. ARNOLD,M. J.; TAPP,S. R. Directmarketing in non-profitservices: investigating the case of the arts industry. Journal of Services Marketing,v. I7,n. 2,p. I4I-I60,2003.

BOWEN,D.; SIEHL,C.; SCHNEIDER,B. A framework for analyzing customer service orientations in manufacturing. Academy of Management Review,Los Angeles,v. I4,n. I,p. 75-95,I989.

BRADLEY,B.; JANSEN,P.; SILVERMAN,L. The nonprofit sector's \$ Ioo billion opportunity. Harvard Business Review,p. 94-I03,May 2003.

CASTRO JUNIOR,F. H. F. de. Previsão de insolvência de empresas brasileiras usando análise discriminante, regressão logística e redes neurais. 2003. Dissertação (Mestrado) - Universidade de São Paulo, São Paulo,2003.

CORRAR,L. J. Pesquisa operacional para decisão emadministração. São Paulo: Atlas,2004.

CRUZ,C. M.; ESTRAVIZ,M. Captação de diferentes recursos para organizações sem fins lucrativos. São Paulo: Global,2000. I58 p.

DEARO,F. Curso de captação de recursos e marketing social. São Paulo,2004.

DESMET,P. Asking for less to obtain more. Journal of Interactive Marketing,v. I3,n. 3,p. 55-65, Summer I999.

FAY,E. The rise-and fall?-of face-to-face fundraising in the United Kingdom. New Directions for Philanthropic Fundraising,n. 33,p. 83-94,Fall 200I.

FISHER,R. M. Estado,mercado e terceiro setor: uma análise conceitual das parcerias intersetoriais. Revista de Administração da USP,v. 40,n. I,p. 5-I8,jan./fev./mar. 2005.

FONSECA,G. M. da; MOORI,R. G.; ALVES,M. A. Cooperação intersetorial (empresas privadas e organizações do terceiro setor): uma visão baseada em valor. In: ENCONTRO NACIONAL DA ASSOCIAÇÃO NACIONAL DOS PROGRAMAS DE PÓS-GRADUAÇÃO EM ADMINISTRAÇÃO (ENANPAD),29,2005,Brasília. Anais do XIX Enanpad,Brasília: Anpad,2005.

FRANCO,J.; PEREIRA,M. F.; SARTORI,R. Captação de recursos para o terceiro setor: um estudo na cidade de Maringá-PR. In: ENCONTRO NACIONAL DA ASSOCIAÇÃO NACIONAL DOS PROGRAMAS DE PÓS-GRADUAÇÃO EM ADMINISTRAÇÃO (ENANPAD), 27,2003, Atibaia. Anais do XXVII Enanpad. Atibaia: Anpad,2003. (I CD-ROM).

GAINER,B.; PADANYI,P. Applying the marketing conceptto cultural organizations: an empirical study of the relationship between marketorientation and performance. International Journal of Nonprofit and Voluntary Sector Marketing,v. 7,n. 2,p. I82-193,2002.

HAIR JUNIOR,J. F. etal. Análise multivariada de dados. 5. ed. Porto Alegre: Bookman,2005.

HAMZA,K. M.; VELOSO,A. R.; TOLEDO,G. L. Comunicação integrada de marketing em organizações sem fins lucrativos. In: ENCONTRO NACIONAL DA ASSOCIAÇÃO NACIONAL DOS PROGRAMAS DE PÓS-GRADUAÇÃO EM ADMINISTRAÇÃO (ENANPAD),29,2005,Brasília. Anais... Brasília: Anpad,2005.

HIGGINS,J. W.; LAUZON,L. Finding the funds in fun runs: exploring physical activity eventas fundraising tools in the nonprofitsector. International Journal of Nonprofit and Voluntary Sector Marketing,v. 8,n. 4,p. 363-377,2003.

HUDSON,M. Administrando organizações do terceiro setor: o desafio de administrar sem receita. São Paulo: Makron Books,I999. 
KINGSTON,J.; BOLTON,M. New approaches to funding not-for-profitorganisations. International Journal of Nonprofit and Voluntary Sector Marketing,v. 9,n. 2,p. II2-I2I,2004.

KOTLER,P. Marketing para organizações que não visamlucro. São Paulo: Atlas,I978.

KOTLER,P.; ARMSTRONG,G. Princípios de marketing. 9. ed. São Paulo: Prentice Hall,2003.

KOTLER,P.; LEVY,J. Broadening the conceptof marketing. Journal of Marketing, v. 33,p. I65-I74, Jan. I969.

KOTLER,P.; ZALTMAN.,G. An aproach to planned social change. Journal of Marketing,n. 35, Oct./Nov. I97I.

KOTTASZ,R. How should charitable organizations motivate young professionals to give philanthropically? International Journal of Nonprofit and Voluntary Sector Marketing,v. 9,n. I,p. 9-27, 2004 .

LEVITT,T. A imaginação de marketing. São Paulo: Atlas,I990.

LEVY,J. D. The growth of fundraising: framing the impactof research and literature on education and training. New Directions for Philanthropic Fundraising,n. 43,p. 2I-30,Spring 2004.

MACHADO,U. L. S.; VERDINELLI,M. A análise multidimensional como subsídio para sustentabilidade de micro e pequenas empresas. In: Anais... Santa Catarina: Univali/Slade,2004.

MACHADO,E. C. de A. etal. Marketing de relacionamento,trocas sociais e identidade saliente: construção de um modelo no terceiro setor. In: ENCONTRO NACIONAL DA ASSOCIAÇÃO NACIONAL DOS PROGRAMAS DE PÓS-GRADUAÇÃO EM ADMINISTRAÇÃO (ENANPAD), 29,2005,Brasília. Anais do XXIX Enanpad. Brasília: Anpad,2005. (I CD-ROM).

MARCUELLO,C. Approaching the third sector from a management perspective: whatdoes this offer? Trento: University of Trento,Dec. 200I.

MARTINEZ,C. V. Social alliances for fundraising: how Spanish nonprofits are hedging the risks. Journal of Business Ethics,v. 47,p. 209-222,2003.

MEREGE,L. C. Administração do terceiro setor. Um novo próspero campo de trabalho. 2000. Disponível em: <http://200.I8.48.I23/editorial.htm>. Acesso em: 3 abr. 2005.

MURPHY,J. C. Foundation fundraising for new organizations. New Directions for Philantropic Fundraising,n. 28,p. 5-I7,Summer 2000 .

MURPHY,T. B. Financial and psychological determinants of donors' capacity to give. New Directions for Philanthropic Fundraising,n. 29,Fall 200ob.

NEWMAN,W. H.; WALLENDER,H. W. Managing not-for-profitenterprises. Academy of Management Review,p. 24-3I,Jan. I978.

NICHOLS,J. E. Repositioning fundraising in the $2 \mathrm{I}^{\text {st }}$ century. International Journal of Nonprofit and Voluntary Sector Marketing,v. 9,n. 2,p. I63-170,2004.

O'HEFFERNAN,P. Raising money internationally: foundations and beyond. New Directions for Philanthropic Fundraising,n. 26,p. 51-66,Summer 2000.

PEATTIE,S. Applying sales promotions competitions to nonprofits contexts. International Journal of Nonprofit and Voluntary Sector of Marketing,v. VIII,n. 4,2002.

PERREAULT JUNIOR. W. D.; BEHRMAN,D. N.; ARMSTRONG,G. M. Alternative approaches for interpretation of multiple discriminantanalysis in marketresearch. Journal of Business Research, v. 7,p. I5I-I73,I979. 
POPADIUK,S.; MARCONDES R. C. Marketing social como instrumento facilitador de mudanças organizacionais: uma aplicação ao processo de privatização. Cadernos de Pesquisa em Administração, v. I,n. I2,p. 42-53,2000.

RODRIGUES,M. C. P. Demandas sociais versus crise de financiamento: o papel do terceiro setor no Brasil. Revista de Administração Pública,v. 32,n. 5,p. 25-67,set./out. I998.

ROMNEY-ALEXANDER,D. Payroll giving in the UK: donor incentives and influences on giving behaviour. International Journal of Nonprofit and Voluntary Sector Marketing,v. 7,n. I,p. 8.492, 2002.

SALLES,H. K.; DELLAGNELO,E. H. L. A estruturação de organizações ambientalistas do terceiro setor e a relação com o modelo de ava liação de desempenho de suas fontes financiadoras. In: Anais do XXIX Enanpad. Brasília,2005.

SARGEANT,A. Do UK charities have a lotto learn? Fund Raising Management,v. 26,n. 5,p. I4-I6, July I995.

Marketing management for nonprofit organisations. New York: Oxford University Press Inc, I999a.

Charitable giving: towards a model of donor Behaviour. Journal of Marketing Management, v. I5,p. 215-238,1999b.

Fundraising on the web: opportunity or hype? New Directions for Philanthropic Fundraising, n. 33,p. 39-56,Fall 2001 .

SARGEANT,A.; LEE,S. Improving public trustin the voluntary sector: an empirical analysis. International Journal of Nonprofit and Voluntary Sector Marketing,v. 7,n. I,p. 68-83,2002.

SAYER,K. Making the case for investmentin fundraising. International Journal of Nonprofit and Voluntary Sector Marketing,v. 9,n. 2,2004.

SCHIAVO,M. R. Conceito e evolução do marketing social. In: Conjuntura social. São Paulo: Comunicarte,Instituto Ayrton Senna,I999.

SHAPIRO,B. P. Marketing for nonprofitorganizations. Harvard Business Review,p. I23-I32,Sept.Oct. 1978.

SHELLEY,L.; POLONSKY,M. J. Do charitable causes need to segmenttheir currentdonor base on demographic factors?: an Australian examination. International Journal of Nonprofit and Voluntary Sector Marketing,v. 7,n. I,p. I9-29,2002.

STEPHENS,C. R. Building the fundraising team. New Directions for Philanthropic Fundraising,n. 43,p. 83-94,Spring 2004.

TENÓRIO,F G. Um espectro ronda o terceiro setor: o espectro do mercado. Revista de Administração Pública,v. 33,n. 5,p. 85-102,set./out. I999.

TYMINSKI,R. Reducing funding risk and implementing a fundraising plan: a case study. Nonprofit Management \& Leadership,v. 8,n. 3,p. 275-286,Spring 1995.

VALARELLI,L. L. Uma noção ampliada de captação de recursos. 2002. Disponível em: <www.rits. org.br/gestao_teste/ge_home_intro.cfm>. Acesso em: 2 I jul. 2004.

VARADARAJAN,P. R.; MENON,A. Cause-related marketing: a coalignmentof marketing strategy and corporate philanthropy. Journal of Marketing,v. 52,p. 58-74,July I988.

WAGNER,L.; RYAN,F. P. Achieving diversity among fundraising professionals. New Directions for Philanthropic Fundraising,n. 43,p. 63-70,Spring 2004. 
WAYSON,T. Putting the benefitback into fundraising benefits. New Directions for Philanthropic Fundraising,n. 30,p. 79-91,Summer 1998.

WEISBROAD, B. A. The Nonprofit mission and its financing. Journal of Policy Analysis and Management,v. I7,n. 2,p. I65-I74,I998.

WOLF,T. Managing a Nonprofit Organization in the Twenty-First Century. New York: Fireside Edition,I999.

TRAMITAÇÃO

Recebido em 14/8/2006

Aprovado em 29/11/2006 
Copyright of Revista de Administração Mackenzie is the property of Universidade Presbiteriana Mackenzie, RAM-Revista de Administracao Mackenzie and its content may not be copied or emailed to multiple sites or posted to a listserv without the copyright holder's express written permission. However, users may print, download, or email articles for individual use. 